Key messages:

1. The internet can provide an appropriate channel for information and support for new fathers who have limited contact with health professionals around the time of the birth

2. Fathers are initially drawn to information which links their role to active interaction with the infant.

3. Fathers with internet access may be unable to identify suitable websites to gain information to assist in their parenting.

4. Health authorities should consider tailoring their health information to make it more specific to new fathers

5. Fathers may not be aware of the evidence linking their support of breastfeeding to health benefits for their infant. 


\section{The evaluation of tailored email and web-based information for new fathers}

\section{Abstract}

\section{Background}

Information and advice on infant health and development has been shown to be well received by new parents and to lead to more confident and nurturing parenting. However, in spite of the accumulating evidence highlighting the importance of fathers to the well being of their families, fathers rarely access and utilize 'parenting' information. Tailored information for fathers delivered via email and internet may provide an alternate route for support for fathers. This study aimed to assess father's readiness to utilize electronic information tailored to father's role.

\section{Methods}

Two hundred and fifty three fathers from antenatal classes in two Australian cities were offered email and web-based information on seven topics: Baby play, Breastfeeding, Postnatal Depression, Father-infant bonding, Sex after birth, Work-family balance and Fussy babies. Of 137 who completed consent forms, a total of 105 fathers selected three topics and 67 fathers provided 149 topic evaluations.

\section{Results}

Most respondents were from managerial, professional or skilled occupations and had higher educational qualifications than the general population of fathers. The most popular topics were those that related to father-infant interaction (Baby games and Father-infant 
bonding) and the least popular were breastfeeding and sex after the birth. Respondents rated the information as satisfactory and most (78\%) indicated that it changed their approach to fathering. Although the websites provided were available through the internet few fathers had previously accessed them.

\section{Conclusions}

Information tailored to new father's perspectives provided through email or internet may increase new fathers' access to useful knowledge and support. Important health topics such as breastfeeding may not currently be perceived as particularly relevant to fathers in the antenatal period. Portals designed to filter existing websites could facilitate the use of parenting information by new fathers. 


\section{Introduction}

Information and advice on infant health and development allows parents to understand the needs and capabilities of their growing infant, to offer appropriate care and to make reasonable judgments of when to seek professional help (Riley, Meinhardt, Nelson, Salisbury, \& Winnett, 1991). Newsletters containing information on child development at different stages have been shown to be well received by new parents and to lead to more confident and nurturing parenting behaviours (Cudaback et al., 1985; Riley et al., 1991). Recently, however, it has been recognized that while support is typically described as for 'parents,' fathers of new infants do not access or utilize the information or services provided (Creasey \& Trikha, 2004; FACS, 2004; Sarkadi \& Bremberg, 2004). Although mothers and fathers may share information, those attempting to extend the provision of parenting information to include fathers have no guidance on which areas of information fathers will seek or what formats might effectively include fathers (Waterson \& Welsh, 2006). In the light of the accumulating evidence highlighting the importance of fathers to the well being of their families, the lack of information and support reaching fathers is of concern (M. Lamb, \& Tamis-Lamonda, 2004; Russell et al., 1999).

\section{Father's information and support needs}

A number of issues can be identified as important to fathers by virtue of their having the care of a young infant. For example, new fathers must establish a routine, with their partners, to reliably settle their baby to sleep. Infants vary widely in their progress toward self-regulation and although most babies have established a Circadian rhythm by four months of age a large proportion of parents (approximately 30\%) have a significant 
problem settling their infant (Armstrong, Quinn, \& Dadds, 1994). As well, for a percentage of babies wakefulness will be accompanied by distress and estimates of 'colic' (excessive crying) among infants in the first months ranges from 10\% to 54\% (Armstrong et al., 1994; St James-Roberts \& Halil, 1991). Prolonged sleep disruption and the stresses of an unsettled or colicky baby can, in turn, impair the wellbeing of both parents (Lam, Hiscock, \& Wake, 2003; Martin, Hiscock, Hardy, Davey, \& Wake, 2007). Father's own mental health may suffer in the postpartum period (Matthey, Barnett, Kavanagh, \& Howie, 2001; Matthey, Barnett, Ungerer, \& Waters, 2000) but a more common scenario is where the father is affected by the postnatal depression of his partner (Gjerdigen \& Center, 2003). Studies from a variety of locations suggest between 10 and 20 per cent of mothers will be suffering from Post Natal Depression so that a considerable number of fathers face the issues of supporting a depressed mother while managing the new baby's needs (Armstrong et al., 1994; Milgrom, Martin, \& Negri, 1999). Additional issues for fathers identified in the literature on family formation include: resuming a sexual relationship after the birth; supporting mother's initiation and maintenance of breastfeeding; and, managing their return to work (M. Lamb, \& TamisLamonda, 2004). Qualitative studies of new fathers have also identified fathers' uncertainty in establishing a role while wishing to form a bond with their newborn (Barclay \& Lupton, 1999; Jordan, 1990; Nystrom \& Ohrling, 2004).

A major difficulty in addressing these needs however is the lack of fathers' face-to-face contact with health professionals. From the time that the pregnancy is confirmed the mother becomes the patient of the health service and her pregnancy becomes the focus of 
visits with her general practitioner or midwife or to the hospital antenatal clinic (Fletcher, Matthey, \& Marley, 2006).

A method of delivering information which may be particularly suited to new fathers is via the new information technologies; internet and electronic mail services that can provide multiple information sources tailored to the characteristics or interests of particular groups. Because time pressure is frequently cited by fathers as a barrier to involvement and fathers, on average, return to work soon after the birth, the supply of information and support without the need for face-to-face contact would seem a promising strategy (Bittman, 2004; Russell et al., 1999). The use of internet and computer-assisted communication also fits with the evidence that males make more frequent use of internet and use it for seeking information more than females (Shaw \& Gant, 2002).

\section{Tailoring health information and support to fathers}

While the internet seems to offer an avenue for communicating with new fathers it cannot be assumed that locating parenting information on the World Wide Web will effectively engage fathers. A recent study of a popular Swedish website promoted as a 'parenting' website for mothers and fathers found that $84 \%$ of users were female (Sarkadi \& Bremberg, 2004). Tailoring the parenting information so that it clearly applies specifically to fathers in their role with a new baby may be required to improve fathers' uptake and use of parenting information. 
A variety of studies examining health behaviours have demonstrated that health promoting information messages tailored to participants' demographic, psychosocial and behavioural characteristics are more effective than generic health promotion information (de Nooijer, Lechner, \& de vries, 2002; Kreuter, Bull, Clark, \& L., 1999). When compared to generic health information (in print form) tailored information has been found to be more likely to be read and remembered, more often discussed with others and to be perceived as more interesting and personally relevant (Dijkstra, 2005; Dijkstra \& De Vries, 1999; Kreuter et al., 1999; Schore, 1994). Tailored messages are effective, it is argued, because they reduce superfluous information, link to prior knowledge, allow staged health behaviour messages and encourage thoughtful consideration because the messages are perceived as more relevant (de Nooijer et al., 2002; Dijkstra, 2005; Kreuter et al., 1999; Pasick, 2001). By contrast, simply 'personalising' health information, by using the participants name at the head of generic material, does not improve effectiveness (Kreuter \& Strecher, 1996).

In the case of parenting information for fathers, much of the information provided to parents is, at best, 'personalised' in the sense that fathers are mentioned in the title or presumed to fall under the heading of 'parent' without the information being tailored to take account of the perspective, values, abilities and prior knowledge of fathers. Whether tailoring would be sufficient to attract the interest of fathers, and whether they would find tailored information useful, however, is not known.

\section{Aims of the study}


Based on the above overview, the following three questions arose and thus comprised the principal aims of our study:

1. Will men who are about to become fathers take advantage of email and webbased information if it is tailored to relate specifically to their role?

2. Are there topics which particularly appeal to new fathers?

3. Will fathers find email and web-based information useful in their fathering role?

\section{Method}

Expectant fathers attending antenatal education classes at four hospitals in Newcastle, New South Wales and Hobart, Tasmania were offered information and support, if they had access to internet and email) as part of a randomized control trial conducted over 12 months until November 2006 (the results of the trial are reported elsewhere). The total number of men attending the 33 classes over this period was 253 of whom 190 were estimated to have access to internet (Australian Bureau of Statistics, 2000).( Due to privacy concerns fathers were not directly asked if they had internet access). One hundred and thirty seven completed consent forms (137/190;72\%) and of these, 105 (77\%) completed antenatal online surveys (a condition for receiving the information and support from the project). These fathers were sent email packages containing information and links to follow-on websites. The results reported below are drawn from the responses of the 105 fathers who, as part of the antenatal online survey, selected three topics and the responses of 67 fathers (49\% of those receiving packages) who provided evaluation of 
the information.

\section{Procedure}

Expectant fathers were invited to help test an email-and-web based information package

for fathers. Those who completed the consent form were sent an introductory letter accompanied by a "New Fathers Information Project" DVD. A test email was also sent to facilitate correction of any incorrect addresses. Participants then completed the online survey and selected three information packages (out of seven) to be emailed to them. A short evaluation form was included with each package. When the evaluation form was returned the next package was sent usually within four days.

\section{Materials for fathers}

A 'starter pack' was mailed to all participants comprising a brief (12 minute) introductory DVD comprising video clips illustrating the connection between infants' intimate relationships and brain development, basic fathering skills (settling and bathing) and demonstrating father-infant holding. The accompanying briefing sheet explained the procedures for completing the online survey and the receipt of email information.

Public health perspectives involving the father's role in support of the mother (breastfeeding, postnatal depression) and father-infant role perspectives (baby games, father-infant bonding) were utilised to select appropriate themes for information packs. Topics were identified via the literature on the transition to fatherhood, through ongoing 
discussions with fathers attending antenatal sessions (approximately 300 fathers in total) and through discussions with other educators. The seven topics offered to fathers in the study and the questions used for description of the package (in italics) were: Father-baby games What games can I play with my new baby? What can new babies do apart from eat, sleep and make a mess? ; Fathers helping breastfeeding How many times will we be feeding? What about storing breast milk? How can I help? ; Father-infant bonding How does father-infant bonding work? How does the bond with my baby make a difference? ; Fathering a fussy baby Is there a good way to get them to sleep? How much sleep is normal? What tricks are there?; Sex after the birth How long will it be before we can have sex again? What is usual? What about if she has some surgery? ; Post natal depression How can I recognise that my partner is depressed? How long is it likely to last? What are some important things for me to do? ; and, Work-family balance Switching off and being available. How big a job is fathering anyway? To avoid possible disruptions due to technical difficulties with the emailed documents no images or illustrations were included with the text. The initial documents were tested on fathers prior to the commencement of the study. The final packages included links to websites (except for Father-Infant Bonding and Work-family balance for which no appropriate websites could be located) but were designed as stand alone, father-oriented introductions to the topic indicated.

\section{Example: Father-baby games}

The email contained an introductory paragraph as follows: 


\section{GAMES TO PLAY WITH BABIES}

Although mothers and fathers play many similar games, the way that men and women play with babies is often different. Fathers' interaction with babies is often more energetic and moves more quickly between calming, restful activities and highly stimulating, exciting activities. If the dad is sensitive to what the baby enjoys then babies can use dads' high energy play to learn to regulate their own emotions. On the other hand, learning how to slow down and tune in to the baby is the basic task for all dads. Research suggests that babies benefit from the different styles of interaction that they get from mothers and fathers.

Fathers were directed to an attached WORD document with the following text:

\section{The basic idea}

Games with young babies are very easy as far as equipment goes. You are already the perfect game machine for your baby. You are the expert because the baby is fascinated by you, the dad. Your face, the way you breathe, the way that your hair feels, the way you smile or twist your mouth, all of these things are very interesting to your baby.

\section{Like a tennis match}

Think of it like a special sort of tennis match. You have two players who take turns but the light is very bad and you cannot be sure where the ball is coming from. In a 
game with your baby you have to concentrate and try to see what is going on. You are the pro here, and your baby is a very promising young player. You wiggle your nose or poke out your tongue and then see if your baby does the same.

Remember that you are playing with a fairly junior player and so you have to make allowances. He or she might not get it perfectly, they try to poke out their tongue but it might only just come out past their lips a little bit. But you can see they are trying so you take that as a pretty good return. You try another serve just like the one before. Since you want this player to improve their game, you are happy to repeat the stroke many times while they get the hang of it. You'll know when they get tired of this particular stroke because they will stop returning.

\section{Advanced play}

Advanced play is when you wait to see what sort of stroke the baby will play and then you return it. This is a bit harder and even for professional players like fathers it takes practice and patience. If you watch carefully your baby will try a new activity, it might be scrunching up their eyes or opening their mouth wide. Then you can try imitating it and see what happens.

\section{Feeling silly}

Probably the hardest part of playing games with babies is feeling silly. With real babies you often get it wrong and they don't give you a high five. You probably will end up nodding your head and opening your mouth like a goldfish and your baby will 
do nothing or look the other way. Then you might feel stupid, especially when other adults are looking at you. There is no sure fire way to avoid this. It's part of fathering. If you want what is best for your baby you'll keep going (even when you feel a bit like an idiot). You can be confident that you and your baby will get into synch.

Brief descriptions of four websites, with examples and links, were provided: Games linked to babies' development (http//Happy Babies); Games to play while in the car (www.MomsMinivan.com); Directions for baby massage (www.Fisher-price.com); and, Online computer interaction games for babies (www.Fisher-price.com).

The Evaluation form for each package asked for responses to five questions on a four point scale from Strongly Agree to Strongly Disagree: Q1. This document gave me new information; Q2. I intend to discuss the information with my wife/partner; Q3. I am satisfied with the quality of this information Q4. Because of this information I have decided to do some things differently Q5. I visited one (or more) of the websites.

\section{Results}

The sample of fathers $(n=105)$ who responded were predominantly in managerial, professional or semi professional occupations, a majority (82\%) were married and most (77\%) had further education qualifications. Table 1 compares the sociodemographic characteristics of the respondents to those of a national sample of fathers with a child under two years of age. 
[Table 1 about here]

\section{Topics selected by new fathers}

Fathers indicated when completing their online survey which three out of seven topics they wished to receive information on. Table 2. presents the responses of the 105 fathers who completed the online survey.

[Table 2 about here ]

Overall response to the topics.

It was necessary for fathers to complete and return the evaluation form from each Topic email in order to be sent the next Topic. Of the 105 who completed the initial online survey (and were sent the DVD starter pack and the first Topic on their list) 38 did not return the evaluation form from the first email package, 18 received only two email packages and 49 received all three. In Table 3 the responses of the fathers are given under the four categories offered in the evaluation document. A fifth column reports on the percentage of approval (Strongly Agree plus Agree) to disapproval (Disagree plus Strongly Disagree). The number of fathers indicating that they followed the address given in the package to a website is also given in the table.

[Table 3 about here] 
The number of fathers evaluating the topics ranged from 44 (Father-baby Games) to six (Sex after the birth) preventing direct comparisons of approval across topics. However there was a noticeable variation in the percentage of fathers indicating that they would do something different from $93 \%$ of fathers evaluating Father-baby Games to $50 \%$ of those evaluating Postnatal Depression. At the foot of the response page the final question was “Any other comments about the information?" Out of the 149 email responses $70(47 \%)$ included comments. Responses received were approximately proportional to the number responding to each topic and many were brief. Main themes manifest in the approving comments were as follows: usefulness "has allowed myself to remain calm during crying" (23\%); interesting or new "really made me think how I am to our baby" (19\%); and reinforcing or boosting confidence "has given me a lift in confidence to develop my own style of fathering" (14\%). Critical comments (17\%) related mainly to insufficient information "more specific examples of interaction with the baby would be good", "didn't really seem to be much meat in it".

\section{Discussion}

The results of this study suggest that tailored information delivered in an electronic format may be a feasible means of support for some new fathers. The fathers in this study were willing to complete an online survey in order to obtain father-specific emailed information and the majority of participants $(64 \%)$ were also willing to submit 
evaluations of the information that was emailed to them. Overall, their assessments of the materials were very positive; 96 per cent of responses evaluated the quality of the information as satisfactory. Given the wide availability of web-based material it is also significant that in 95 per cent of cases fathers reported that the information provided was new. Free comments such as "it never occurred to me to look for baby games" and "This sort of info is perfect for dads who want to be involved but don't know where to look" (in response to Father-Infant Bonding package) suggest that it was not lack of time or interest that impeded their obtaining information. The practicality (usefulness) of the information was clearly important and the fathers appreciated the access to information even if the implementation would have to await the baby's arrival. As one father commented "I also found the concepts of baby conversations very interesting. Can't wait to try this out myself". The most frequent criticism of the material was that it was too brief or "lacked depth". These responses suggest that fathers' appreciate information tailored to take account of the particular perspective of a father's role but some may seek more in-depth treatment than was offered in this study.

The most popular topics were those that related to father's direct interaction with the infant. The stimulus of the 'starter pack' DVD may have influenced the choice of Fatherinfant bonding as a topic but it may also reflect the discrepancy between fathers wishing to be involved with their new baby and the lack of role models to provide guidance (Barclay \& Lupton, 1999; Daly \& Palkovitz, 2004). The popularity of Father-baby games also reflects the widely reported preferred interaction style of fathers (Kazura, 2000; Kromelow, 1990; M. Lamb, 1977a; MacDonald, 1986). It is also clear that although the 
information was specifically directed to fathers, the fathers did not see themselves acting in isolation with their infant. In almost every case the fathers intended to discuss the information with their wife or partner. A comment on the sex after the birth package "I now have access to the information that both my wife and I have been wondering about but unable to find satisfactory answers" suggests that in some cases the couple, rather than the father, were the recipients of the information. The fact that 78 per cent of fathers also indicated that they would parent differently as a result of the information suggests that these men comprise a group who are able to be influenced in their approach to raising a new baby.

The least popular topics, breastfeeding and sex after birth, are both known to be important issues for fathers, breastfeeding from a public health perspective and sexual activity as a central ingredient of the couple relationship. Breastfeeding is widely upheld as a key strategy for improving infant health and father's influence on initiation and maintenance of breastfeeding has been documented in numerous studies (Scott \& Binns, 1999). The lack of appeal of this topic for fathers suggests that the current extensive promotion of breastfeeding for new infants has not impacted on father's views of breastfeeding as an activity that is an important part of their role. The package on resuming sexual relationships was also infrequently selected even though the resumption of sexual relationships is an essential step in the transition to parenthood for men and women and many concerns remain unresolved 12 moths after the birth (Condon, Boyce, \& Corkindale, 2004; Pastore, 2007; Polomeno, 1998). The minimal response to this topic among these men prior to birth may be due to the optimistic expectation that sexual 
relations will resume at the same levels of frequency and satisfaction as before conception or during the earlier stages of pregnancy.

The fathers in this sample have particular characteristics which limit the generalizability of these results to the wider population of new fathers. Those attending antenatal education represent $80 \%$ of first time fathers (New South Wales Standing Committee on Social Issues, 1998). Since a requirement of participation in this study was internet access not all fathers in the groups were eligible (25\% of Australian males with income over $\$ 40,000$ have no access; (Australian Bureau of Statistics, 2000). The men whose views are reported in selecting topics comprised 55\% of eligible fathers and the evaluative comments are those of $64 \%$ (67/105) of fathers who were sent the first package.

Comments by fathers in response to reminder emails suggest that non-response to packages did not necessarily indicate dissatisfaction of the information sent. Twenty one non-responders (44\%) replied. Most comments (17/21) explained work pressure or home demands, including premature deliveries, as reasons for not replying and all asked for more packages although they then failed to return the evaluation form. Four were content with their fathering "enjoying fathering to the max will say pass to information" and declined further packages.

The selective nature of participants (highly educated, in managerial, professional or skilled occupations, and with access to computer email and internet) accentuates some of the implications for services wishing to support new fathers. The existence of information on the web did not guarantee that these technologically literate fathers would be able to 
locate father-relevant material. In fact, the scope of information available makes the task of finding useful information more difficult. Searching for the terms 'father' and 'baby', for example, using a popular search engine such as 'Google' retrieves over two million websites, far more than any individual can view. Since almost four in five of these men were willing to change their approach to parenting when provided with tailored information, the provision of more father-specific guides to existing resources would seem to be a promising health promoting strategy. In the health arena web portals have been established to address the oversupply of health information via the internet by filtering, for example, commercially-focused information or extraneous web pages (Fricke, 2005). Portals designed for new fathers may be useful ways to provide fatherspecific and general information to those with access to internet. Web-based material developed for men from a broader range of backgrounds, for example using cartoon images and reduced text as in Parenting in Pictures (Raising Children Network, 2007), may provide resources for materials distributed through print or other media tailored to groups of fathers without internet access.

If fathers are to be supported to share the daily care of their infants then they will require information and advice that is sensitive to their perspective and needs. Web-based support has the flexibility to offer information that is tailored to the particular situation of fathers and to the immediate needs that they identify. This study has identified topics that appear popular with a significant segment of fathers but further testing is required to map the topics which have direct appeal to fathers from a range of backgrounds. Similarly, the effective entry points for new fathers to access father-oriented information remain to be 
web-based information for new fathers

identified. Fathers in this study responded to an invitation to be part of a research project, however, fathers across the community will need to be informed of public entry points to access information and they will also need to be persuaded to log-on to 'give it a go'. 
Table 1.. Sociodemographic characteristics of the initial sample $(n=105)$ compared to the national birth data (Age) and a national sample of fathers with children under two years of age (Education and Occupation).

Study factor

Age

Education*

University/TAFE

Yr 12 complete

Less than Yr 12

Occupation**

Professional/Semi-

professional

Skilled

Unskilled
Study sample

$(n=105)$

33

75

14

11

20

child $<2$ yrs) ${ }^{b}$

$33^{\mathrm{a}}$

61

19
National sample

(fathers with oldest

49

54

37

43

9
9

\footnotetext{
${ }^{\mathrm{a}}$ ABS Births $2005^{\mathrm{b}}$ Unpublished data Australian Bureau of Statistics 2006. Note:

Assume no error in national sample due to large sample and many data sets combined

* $\mathrm{p}$-value for difference $\mathrm{p}=0.01$

** $\mathrm{p}$-value for difference $\mathrm{p}<0.01$
} 
Table 2. Topics (three out of seven) chosen by fathers $(n=105)$

\begin{tabular}{lll}
\hline Topic & Number of & Percentage of \\
& fathers choosing & fathers \\
\hline Father-infant bonding & 85 & $81 \%$ \\
Father-baby games & 77 & $73 \%$ \\
Fathering a fussy baby & 49 & $46 \%$ \\
Work-family balance & 38 & $36 \%$ \\
Postnatal Depression & 30 & $29 \%$ \\
Fathers helping breastfeeding & 17 & $16 \%$ \\
Sex after the birth & 17 & $16 \%$ \\
\hline
\end{tabular}


Table 3. Responses to the evaluation questions for all information packages $(\mathrm{n}=149$ responses from 67 fathers)

\begin{tabular}{|c|c|c|c|c|c|}
\hline Question & $\begin{array}{l}\text { Strongly } \\
\text { Agree }\end{array}$ & Agree & Disagree & $\begin{array}{l}\text { Strongly } \\
\text { Disagree }\end{array}$ & $\begin{array}{l}\text { Agree or } \\
\text { Strongly } \\
\text { Agree (\%) }\end{array}$ \\
\hline Q1. This document & 55 & 86 & 8 & 0 & $95 \%$ \\
\hline gave me new & $(37 \%)$ & $(58 \%)$ & $(5 \%)$ & $(0 \%)$ & \\
\hline information & & & & & \\
\hline Q2I intend to discuss & 80 & 64 & 4 & 0 & $97 \%$ \\
\hline the information with & $(54 \%)$ & $(43 \%)$ & $(3 \%)$ & $(0 \%)$ & \\
\hline my wife/partner & & & & & \\
\hline Q3. I am satisfied with & 40 & 102 & 6 & 0 & $96 \%$ \\
\hline the quality of this & $(27 \%)$ & $(68 \%)$ & $(4 \%)$ & $(0 \%)$ & \\
\hline information & & & & & \\
\hline Q4. Because of this & 16 & 100 & 32 & 0 & $78 \%$ \\
\hline information I have & $(11 \%)$ & $(67 \%)$ & $(21 \%)$ & $(0 \%)$ & \\
\hline decided to do some & & & & & \\
\hline things differently & & & & & \\
\hline Websites & Yes & & No & & \\
\hline
\end{tabular}


web-based information for new fathers

Q5 Visit website(s)?* $60(65 \%) \quad 32(35 \%)$

*Two packages had no websites links

\section{References:}

Armstrong, K., Quinn, R., \& Dadds, M. (1994). The Sleep Patterns of Normal Children. Medical Journal of Australia, 161(3), 202-206.

Australian Bureau of Statistics. (2000). Use of the Internet by Householders.

Barclay, L., \& Lupton, D. (1999). The experiences of new fatherhood: a socio-cultural analyis. Journal of advanced nursing., 29(4), 1013-1020.

Bittman, M., Hoffaman, S., \& Thompson, D. (2004). Men's uptake of family-friendly employment provisions. (No. Research paper No. 22): Australian Government Department of Family and Community Services.

Condon, J. T., Boyce, P., \& Corkindale, C. J. (2004). The First-Time Fathers Study: a prospective study of the mental health and well-being of men during the transition to parenthood. Australian and New Zealand Journal of Psychiatry, 38(56-64).

Creasey, R., R., \& Trikha, S. (2004, Monday March 20, 2006 (downloaded)). Meeting Parents' Needs for Information: Evidence from the 2001 Home Office Citizenship Survey: Research Development and Statistics Directorate Home Office Online Report 48/04. Retrieved Monday March 20, 2006, from http://www.monitoringgroup.co.uk/News\%20and\%20Campaigns/research\%20material/Local\%20Gover nment/rdsolr4804.pdf

Cudaback, D., Darden, C., Nelson, P., O'Brien, S., Pinsky, D., \& Wiggins, E. (1985). Becoming Successful Parents: Can Age-Paced Newsletters Help? Family Relations, 34(2), 271-275.

Daly, K., \& Palkovitz, R. (2004). Guest editorial: reworking work and family issues for fathers. Fathering, 2(3), 211-213.

de Nooijer, J., Lechner, L., \& de vries, H. (2002). Tailored versus general information on early detection of cancer: a comparison of the reactions of Dutch adults and the impact on attitudes and behaviors. Health Education Research Theory \& Practice, $17(2), 239-252$.

Dijkstra, A. (2005). Working Mechanisms of Computer-Tailored Health Education: Evidnece from Smoking Cessation. Health Education Research Theory \& Practice, 20(5), 527-539.

Dijkstra, A., \& De Vries, H. (1999). The Development of Computer-Generated Tailored Interventions. Patient Education and Counseling, 36, 193-203.

FACS. (2004). Parenting Information Project. Volume One: Main Report., from www.facs.gov.au/pip

Fletcher, R., Matthey, S., \& Marley, C. G. (2006). Addressing Depression and Anxiety Among New Fathers. Medical Journal of Australia, 185, 461-463.

Fricke, M., Fallis, D., Jones, M., Luszko, G.M. (2005). Consumer health information on the internet about carpal tunnel syndrome: Indicators of accuracy. The American Journal of Medicine, 118, 168-174. 
Gjerdigen, D. K., \& Center, B. A. (2003). First time parents prematal to postpartum changes in health; and the relation of postpartum health to work and partner characteristics. Journal of the American Board of Family Practice, 16, 304-311.

Jordan, P. L. (1990). Laboring for relevance: Expectant and new fatherhood. Nursing Research, 39(1), 11-16.

Kazura, K. (2000). Fathers' qualitative and quantitative involvement: an investigationn of attachment, play, and social interactions. The Journal of Men's Studies, 9, 41-47.

Kreuter, M. W., Bull, F. C., Clark, E. M., \& L., O. D. (1999). Understanding How People Process Health Information: A Comparison of Tailored and Nontailored WeightLoss Materials. Health Psychology, 18(5), 487-494.

Kreuter, M. W., \& Strecher, D. (1996). Do tailored behavior change messages enhance the effectiveness of health risk appraisal? Results from a randomized trial. Health Education Research Theory \& Practice, 11(1), 97-105.

Kromelow, S., Harding, C., \& Touris, M. (1990). The role of the father in the development of stranger sociability during the second year. American Journal of Orthopsychiatry, 60(4), 521-530.

Lam, P., Hiscock, H., \& Wake, M. (2003). Outcomes of Infant Sleep Problems: A Longitudinal Study of Sleep, Behavioor, and Maternal Well-Being. Pediatrics, 111(3), 203-207.

Lamb, M. (1977a). The development of mother-infant and father-infant attachments in the second year of life. Developmental Psychology, 13(6), 637-648.

Lamb, M., \& Tamis-Lamonda. (2004). The role of the father: an introduction. In M. Lamb (Ed.), The role of the father in child development (4th edition ed.). New Jersey: John Wiley \& Sons.

MacDonald, K. B., \& Parke, R. D. (1986). Parent-child physical play: The effects of sex and age of children and parent. Sex Roles, 15, 367-378.

Martin, J., Hiscock, H., Hardy, P., Davey, B., \& Wake, M. (2007). Adverse Associations of Infant and Child Sleep Problems and Parent Health: An Australian Population Study. Pediatrics, 119, 947-955.

Matthey, S., Barnett, B., Kavanagh, D., \& Howie, P. (2001). Validation of the Edinburgh Postnatal Depression Scale for men, and comparison of item endorsement with their partners. Journal of Affective Disorders, 64(2-3), 175-184.

Matthey, S., Barnett, B., Ungerer, J., \& Waters, B. (2000). Paternal and maternal depressed mood during the transition to parenthood. Journal of Affective Disorders, 60(2), 75-85.

Milgrom, J., Martin, P. R., \& Negri, L. (1999). Treating Postnatal Depression. A Psychological Approach for Health Care Practitioners. Chichester: Wiley.

New South Wales Standing Committee on Social Issues. (1998). Working for children: Communities supporting families. Inquiry into parent education and support programs. Sydney, Australia: New South Wales Government.

Nystrom, K., \& Ohrling, K. (2004). Parenthood experiences during the child's first year: literature review. Journal of Advanced Nursing, 46(3), 319-330.

Pasick, R. J. (2001). Response to Kreuter and Skinner. Health Education Research Theory and Practice, 16(4), 503.

Pastore, L., Owens, A \& Raymond, C. (2007). Postpartum sexuality concerns among first-time parents from one U.S. academic hospital. the Journal of Sexual 
Medicine, Volume 4(Issue 1), 115-123.

Polomeno, V. (1998). Labour and Birth: Supporting a Couple's Intimacy, Part 1. International Journal of Childbirth Education, 13(2), 18-23.

Raising Children Network. (2007). from http://raisingchildren.net.au/

Riley, D., Meinhardt, G., Nelson, C., Salisbury, M. J., \& Winnett, T. (1991). How Effective Are Age-Paced Newletters for New Parents? A Replication and Extension of Earlier Studies. Family Relations, 40(3), 247-253.

Russell, G., Barclay, L., Edgecombe, G., Donovan, J., Habib, G., Callaghan, H., et al. (1999). Fittling fathers into families: men and the fatherhood role in contemporary Australia. Canberra, ACT: Commonwealth Department of Family and Community Services.

Sarkadi, A., \& Bremberg, S. (2004). Socially unbiased parenting support on the Internet: a cross-sectional study of users of a large Swedish parenting website. Child: Care, Health and Development, 31(1), 43-52.

Schore, A. N. (1994). Affect Regulation and the Origin of the Self: The Neurobiology of Emotional Development. Mahwah, New Jersey: Erlbaum.

Scott, J. A., \& Binns, C. W. (1999). Factors Associated With the Initiation and Duration of Breastfeeding: A Review of the Literature. Breastfeeding Review, 7(1), 5-16.

Shaw, L. H., \& Gant, L. M. (2002). Users Divided? Exploring the Gender Gap in Internet Use. CyberPsychology and Behavior, 5(6), 517-527.

St James-Roberts, I., \& Halil, T. (1991). Infant Crying Patterns in the First Year: Normal Community and Clinical Findings. Journal of Child Psychology \& Psychiatry, 32(6), 951-960.

Waterson, T., \& Welsh, B. (2006). Helping Fathers Understand their Infant: A Pilot Study of a Parenting Newsletter. Community Practitioner, 79(9), 293-295. 